\title{
Normal Topography and Binocularity of the Superior Colliculus in Strabismus
}

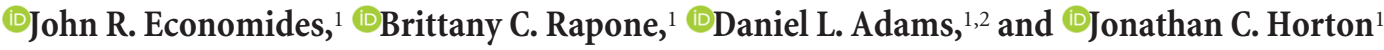 \\ ${ }^{1}$ Beckman Vision Center, Program in Neuroscience, University of California San Francisco, San Francisco, California 94143, and ${ }^{2}$ Center for Mind/Brain \\ Sciences, The University of Trento, Trento, Italy
}

In subjects with alternating strabismus, either eye can be used to saccade to visual targets. The brain must calculate the correct vector for each saccade, which will depend on the eye chosen to make it. The superior colliculus, a major midbrain center for saccade generation, was examined to determine whether the maps serving each eye were shifted to compensate for strabismus. Alternating exotropia was induced in two male macaques at age 1 month by sectioning the tendons of the medial recti. Once the animals grew to maturity, they were trained to fixate targets with either eye. Receptive fields were mapped in the superior colliculus using a sparse noise stimulus while the monkeys alternated fixation. For some neurons, sparse noise was presented dichoptically to probe for anomalous retinal correspondence. After recordings, microstimulation was applied to compare sensory and motor maps. The data showed that receptive fields were offset in position by the ocular deviation, but otherwise remained aligned. In one animal, the left eye's coordinates were rotated $\sim 20^{\circ}$ clockwise with respect to those of the right eye. This was explained by a corresponding cyclorotation of the ocular fundi, which produced an A-pattern deviation. Microstimulation drove the eyes accurately to the site of receptive fields, as in normal animals. Single-cell recordings uncovered no evidence for anomalous retinal correspondence. Despite strabismus, neurons remained responsive to stimulation of either eye. Misalignment of the eyes early in life does not alter the organization of topographic maps or disrupt binocular convergence in the superior colliculus.

Key words: exotropia; microstimulation; retinotopic map; saccade; strabismus; superior colliculus

\section{Significance Statement}

Patients with strabismus are able to make rapid eye movements, known as saccades, toward visual targets almost as gracefully as subjects with normal binocular alignment. They can even exercise the option of using the right eye or the left eye. It is unknown how the brain measures the degree of ocular misalignment and uses it to compute the appropriate saccade for either eye. The obvious place to investigate is the superior colliculus, a midbrain oculomotor center responsible for the generation of saccades. Here, we report the first experiments in the superior colliculus of awake primates with strabismus using a combination of single-cell recordings and microstimulation to explore the organization of its topographic maps.

\section{Introduction}

In alternating exotropia, patients enjoy normal acuity (Buck et al., 2009; Hoyt and Pesic, 2012) and, by definition, are able to use either eye to acquire a visual target (Jampolsky, 1963; Nusz et al., 2006). Usually, the target's location is perceived via the same eye

Received Sept. 8, 2017; revised 0ct. 30, 2017; accepted Nov. 8, 2017.

Author contributions: J.R.E., D.L.A., and J.C.H. designed research; J.R.E., B.C.R., D.L.A., and J.C.H. performed research; J.R.E. and D.L.A. analyzed data; J.R.E., D.L.A., and J.C.H. wrote the paper.

This work was supported by the National Eye Institute-National Institutes of Health (Grants EY10217 to J.C.H. and EY02162 to the Beckman Vision (enter) and by Research to Prevent Blindness (unrestricted grant and Physician

Scientist Award). We thank Jessica Wong for assistance with computer programming.

The authors declare no competing financial interests.

Correspondence should be addressed to Jonathan C. Horton, M.D., Ph.D., Beckman Vision Center, University of California, 10 Koret Way, San Francisco, CA 94143. E-mail: hortonj@vision.ucsf.edu.

DOI:10.1523/JNEUROSCI.2589-17.2017

Copyright $\odot 2018$ the authors $\quad 0270-6474 / 18 / 380173-10 \$ 15.00 / 0$ that makes a saccade to it. However, subjects are capable of using one eye to locate a target and then making a saccade to it with the other eye. This remarkable phenomenon is termed a "crossover saccade" (Agaoglu et al., 2014; Economides et al., 2014). Regardless of which eye they use, patients with alternating exotropia make saccades to visual targets with impressive accuracy (Griffiths et al., 2011; Niechwiej-Szwedo et al., 2017). This is true despite the fact that the appropriate saccade magnitude and direction is different for each eye. It is unknown how the brain calculates the correct vector for the eye that is destined to capture the target.

To answer this question, it makes sense to begin in the superior colliculus and then move upstream in the visuomotor system. The stratum griseum superficiale is populated by binocular cells with receptive fields organized into a retinotopic map (Fig. 1). 

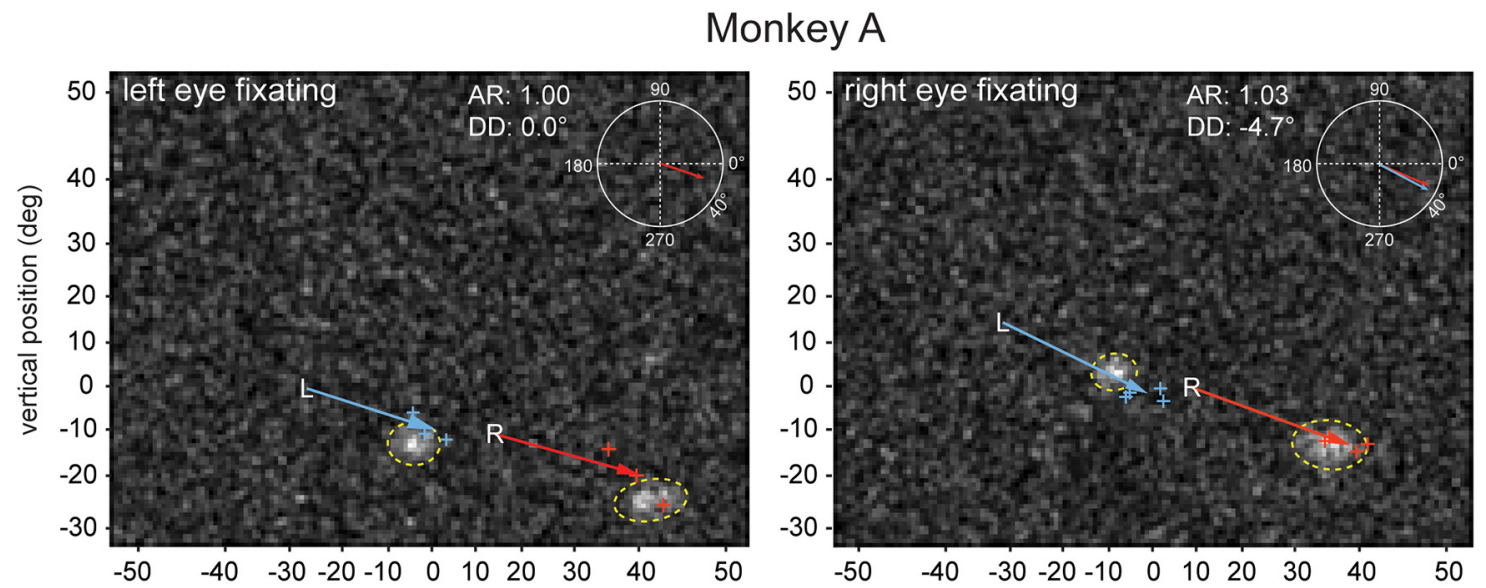

Monkey B
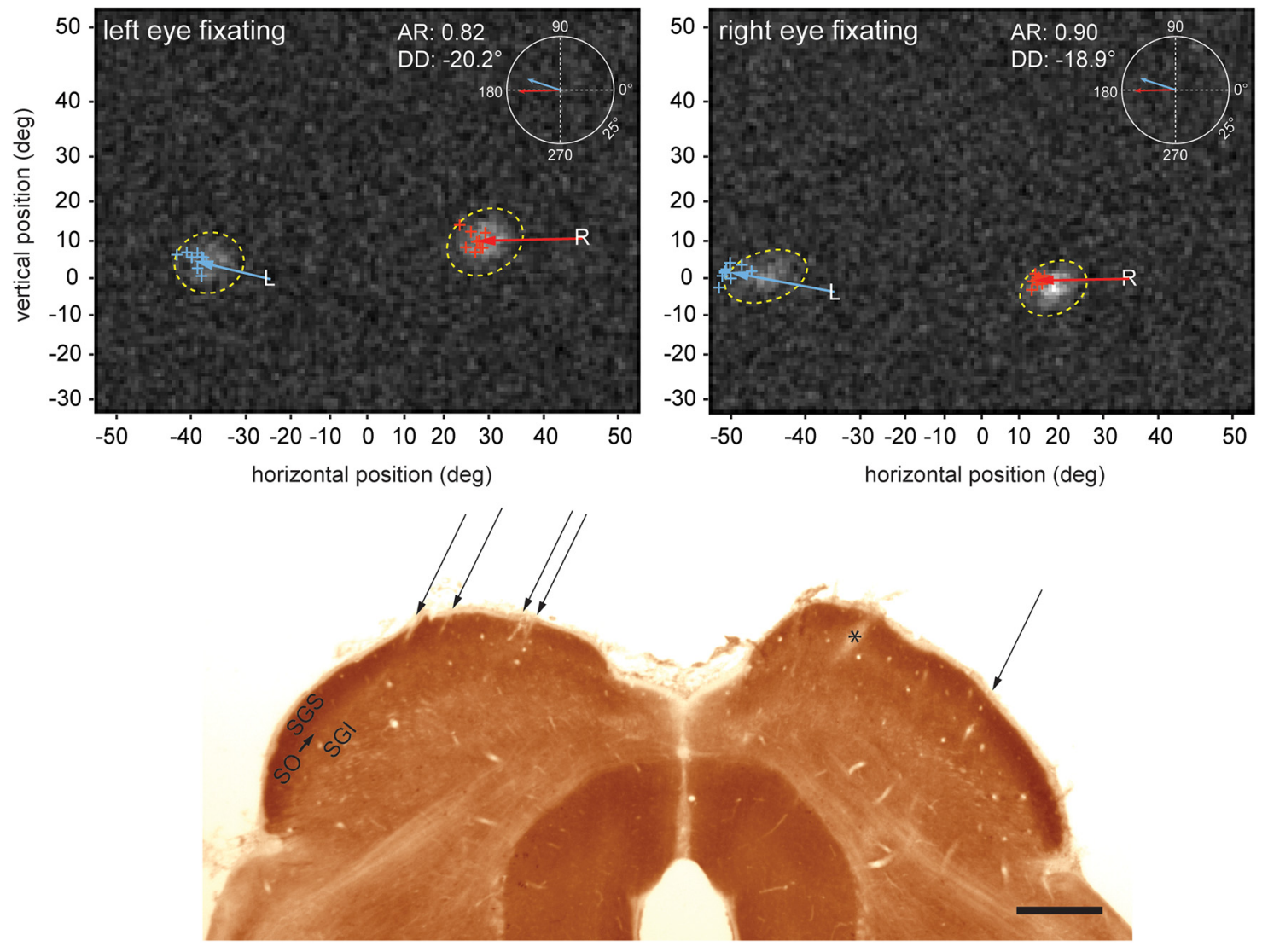

Figure 1. Saccades drive eyes to locations of receptive fields. Sparse noise maps show receptive fields in each eye, with the yellow dashes representing 2 SDs above background (see Materials and Methods). $R$ and L, Mean positions of the right and left foveal projections, respectively. Colored arrows are mean vectors for right eye (red) and left eye (blue) saccades evoked by repeated microstimulation at the recording site in the superior colliculus; crosses denote individual trials. Saccade vectors (insets) are similar in Monkey A, but in Monkey B, the left eye's saccades are rotated $\sim 20^{\circ}$ clockwise with respect to those of the right eye. The left eye's responses are also weaker because the receptive field partly overlaps the blind spot. The main point is that, in both animals, saccades terminate close to the location of receptive fields. AR, Amplitude ratio (saccade amplitude OS/saccade amplitude OD); DD, direction difference (polar angle 0S - polar angle OD). Cytochrome oxidase section shows electrode tracks (arrows) through the superior colliculus and a lesion $\left({ }^{*}\right.$ ) made during the last recording session. SGS, Stratum griseum superficiale; SO, stratum opticum; SGI, stratum griseum intermediale. Scale bar, $1 \mathrm{~mm}$.

In register with this map, the deeper stratum griseum intermediale contains sensory/motor cells that generate a saccade to bring the foveae to the locus of the receptive fields (Robinson, 1972; Schiller and Stryker, 1972; Wurtz and Albano, 1980; Schiller, 1984; Basso and May, 2017). In strabismus, a given visual target will evoke a sensory response at two separate loci within the superior colliculus if the topographic map remains normal. To acquire the target with the intended eye, the sensory response at the "wrong" tectal site must be ignored and local motor activation suppressed.

An alternative possibility is that the onset of strabismus early in life induces a change in the topography of the superior colliculus. It has been shown that subjects with alternating exotropia develop "anomalous retinal correspondence" to avoid visual confusion (Cooper and Feldman, 1979; Economides et al., 2012). This phenomenon is a sensory adaptation whereby discordant retinal 
loci become perceptually aligned by a shift of the spatial localization of visual information emanating from one eye (Herzau, 1996). The physiological basis of this compensatory mechanism is obscure, but presumably involves a translocation of sensory coordinates at one or more visual centers in the brain. A topographic shift in the superior colliculus might serve to compensate for strabismus.

To address this possibility, we have mapped sensory receptive fields and then driven saccades via microstimulation. This approach permits comparison of sensory and motor maps for each eye. We have also probed for anomalous retinal correspondence by mapping receptive fields dichoptically. Although strabismic monkeys often make disconjugate saccades, our data showed no evidence for a shift in collicular maps. Moreover, binocular responses remained intact despite onset of strabismus early in life.

\section{Materials and Methods}

Experimental design of exotropia model and statistical analysis. An alternating exotropia was induced in two male Rhesus monkeys (Macaca mulatta) by free tenotomy of each medial rectus muscle at 1 month of age (Economides et al., 2007). The animals were reared at the California National Primate Research Center until old enough for experiments.

Three years later, the animals were transferred to our laboratory. A titanium head post and recording chamber were implanted (Adams et al., $2007,2011)$. The chamber was situated on the right side over the medial parietal cortex just anterior to the lunate sulcus, to avoid penetrations through striate cortex. The chamber provided access to both the right and left superior colliculi. The implantation surgeries and the physiological recordings were performed at the University of California San Francisco. Approval was granted by the Institutional Animal Care and Use Committee.

The two strabismic monkeys featured herein were used to map the alignment of saccades driven by electrical stimulation in a previous study (Economides et al., 2016). Monkey 2 in the earlier study has been christened Monkey A in this present study; Monkey 3 has been renamed Monkey B.

Although acuity was not tested formally, both animals could fixate and track small targets alacritously with either eye. Monkey A had a refraction of $+1.00 \mathrm{OD}$ (oculus dextrus); $-0.75 \mathrm{OS}$ (oculus sinister). There was an exotropia of $40-45^{\circ}$ and a left hypertropia of $10-20^{\circ}$. Monkey B had a refraction of $+2.00 \mathrm{OD} ;+3.00 \mathrm{OS}$. There was an exotropia of $60-65^{\circ}$ and a hypertropia that varied with gaze angle. The range of their ocular versions was described previously (Economides et al., 2016). The strabismus angles in these monkeys were enormous compared with typical values for humans with exotropia, which average $18^{\circ}$ (Adams et al., 2017). This was a virtue for the purposes of this study because it afforded the best chance of detecting any subtle shift in map topography that might occur from strabismus.

Statistical analyses included Pearson correlation, Wilcoxon rank-sum, and Wilcoxon signed-rank tests performed using MATLAB and Igor Pro.

Eye tracking. Physiological recordings were performed with the monkeys seated comfortably in a primate chair. The head was fixed while eye movements were recorded with video-oculography. Dual independent infrared trackers sampling at $60 \mathrm{~Hz}$ provided horizontal and vertical components of each eye's position in time (SensoMotoric Instruments). Because the monkeys had a large exotropia, it was advantageous to use a separate infrared light source for each eye. With each illuminator positioned laterally, we were able to track each eye over a wide range from $30^{\circ}$ nasally to $60^{\circ}$ temporally. The gain and offset of each eye was calibrated independently while its fellow eye was covered.

Custom-built visual stimuli (Cambridge Research Systems) were rearprojected on a tangent screen (HP xb31, $60 \mathrm{~Hz}$; Hewlett Packard). The viewing distance was $57 \mathrm{~cm}$. Appropriate tangent correction was applied to all visual coordinates. Eye and stimulus positions were sampled at $120 \mathrm{~Hz}$ by a Power 1401 data acquisition and control system (Cambridge Electronics Design). Behavior was reinforced with a liquefied food reward.

Neuronal recording. Platinum/tungsten tetrodes sheathed in quartz glass (0.5-1.0 M $\Omega$ ) were advanced into the superior colliculus with a
Mini Matrix microdrive system (Thomas Recording). Precise registration of recording sites was insured by placing a plastic grid containing a matrix of holes with $1 \mathrm{~mm}$ spacing, horizontally and vertically, inside the chamber during recordings. The tetrode fiber (100 $\mu \mathrm{m}$ diameter) was threaded through a 30-gauge guide tube. The guide tube was advanced manually to $5 \mathrm{~mm}$ above the superior colliculus.

The four amplified tetrode channels were recorded digitally at $25 \mathrm{kHz}$ and saved to disk for offline spike sorting. Neuronal units were derived using template matching and principal components analysis in Spike 2 software (Cambridge Electronics Design).

After the last recording session, electrolytic lesions were placed in the superior colliculus by passing a high-frequency biphasic square wave current $(80-120 \mu \mathrm{A}, 25 \mathrm{kHz}, 10 \mathrm{~s})$ through the tip of the central core of the tetrode. Cytochrome oxidase histochemistry confirmed that the lesions were located in the superior colliculus, along with numerous tetrode tracks (Fig. 1).

Sparse noise visual stimulation. Receptive fields for each eye were mapped simultaneously while the monkey fixated a cross $\left(2^{\circ}\right.$ members, $0.1^{\circ}$ thickness) on the tangent screen. It appeared on the left or right side of the center line at an eccentricity equal to approximately half the monkey's deviation angle. The animals alternated fixation depending on which side the target was located.

When fixation was maintained within a prescribed window $\left( \pm 2-3.5^{\circ}\right)$, sparse noise stimuli were displayed (Churan et al., 2012). Each image frame $(1024 \times 768$ pixels $)$ filled the projection field on the tangent screen $\left(1.4 \mathrm{~mm} /\right.$ pixel, $\pm 52^{\circ}$ horizontally) and appeared for $50 \mathrm{~ms}$. Images were composed of $30-40$ square elements $\left(2^{\circ}\right.$ per side) distributed pseudorandomly. The elements were white against a dark background with $99 \%$ contrast. Each image was unique, with the location of individual elements drawn from a predefined random seed.

This flickering sparse noise stimulation drove robust spiking activity in the superior colliculus. When the monkey broke fixation, the image sequence halted. Spikes collected during epochs of nonfixation were ignored. The location of the fixation target switched side every $7.5 \mathrm{~s}(150$ frames). Mapping was typically performed for 15-20 min. A synchronization pulse marking the onset of each frame was recorded at $120 \mathrm{~Hz}$ and a digital text label containing an index for each frame was sampled with a maximum event rate of $300 \mathrm{~Hz}$.

Electrical microstimulation. After some recordings, microstimulation was delivered to the superior colliculus. If the tetrode was located in the stratum griseum superficiale, then a saccade presumably resulted from current spread into the deeper motor layer. This could introduce a small potential error in sensory/motor map alignment. Current consisted of $500 \mu$ s biphasic square wave pulses $(500 \mathrm{~Hz}, 20-400 \mu \mathrm{A}$, applied for 500-1000 ms; STG 1001, MultiChannel Systems). Only the first saccade in each staircase was measured because subsequent saccades are often smaller and more variable (Stryker and Schiller, 1975; Breznen et al., 1996). Subsequent saccades are also sometimes restricted because an eye reaches the limit of its excursion. No recording or stimulation sites were located within the central $3^{\circ}$ to avoid fields that might overlap with the fixation cross.

Fundus photography. Digital images were obtained of the ocular fundi in each animal. Topical tropicamide $1 \%$ and phenylephrine $2.5 \%$ were applied for mydriasis. Each animal was alert, seated in a primate chair, and head fixed. Approximately 30 digital pictures were taken of each eye with a Nikon D-100 digital SLR mounted on a Topcon TRC-FET high speed retinal camera.

Spike-triggered average response. Spike-triggered average stimuli were obtained from the data generated during simultaneous binocular sparse noise receptive field mapping. A peristimulus time histogram of spiking activity was aligned on the appearance of each sparse noise frame to determine a mean spike latency for every unit. Subtracting that latency from the time of occurrence of each spike allowed us to determine which unique sparse noise frame was on the screen when the spike was generated.

The frame index corresponding to each spike was imported into MATLAB. A custom program used the frame index to regenerate the image that occurred before each spike. The images were segregated by right eye versus left eye fixation. The resulting rectangular matrices were 

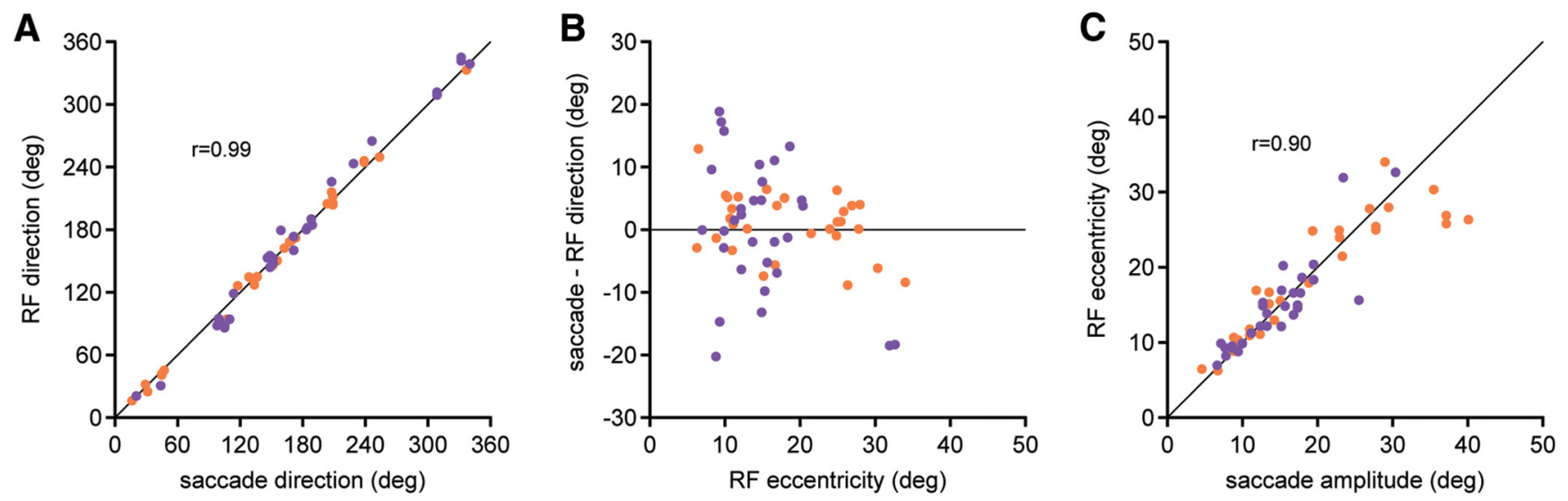

Figure 2. Saccade vectors are correlated with the location of receptive fields. $A$, Receptive field (RF) direction, defined as the polar angle of the vector connecting the fixation point with the center of the RF, is correlated with saccade direction. $\boldsymbol{B}$, The difference between saccade and RF direction is small (mean absolute value $6.2 \pm 5.4^{\circ}$ ) and evenly distributed around $0^{\circ}$. $\boldsymbol{C}$, RF eccentricity is correlated with saccade amplitude. For all graphs, each point represents the mean of four values: right and left eye parameters during right and left eye fixation trials. Orange points are Monkey $\mathrm{A}$ and purple points are Monkey B.
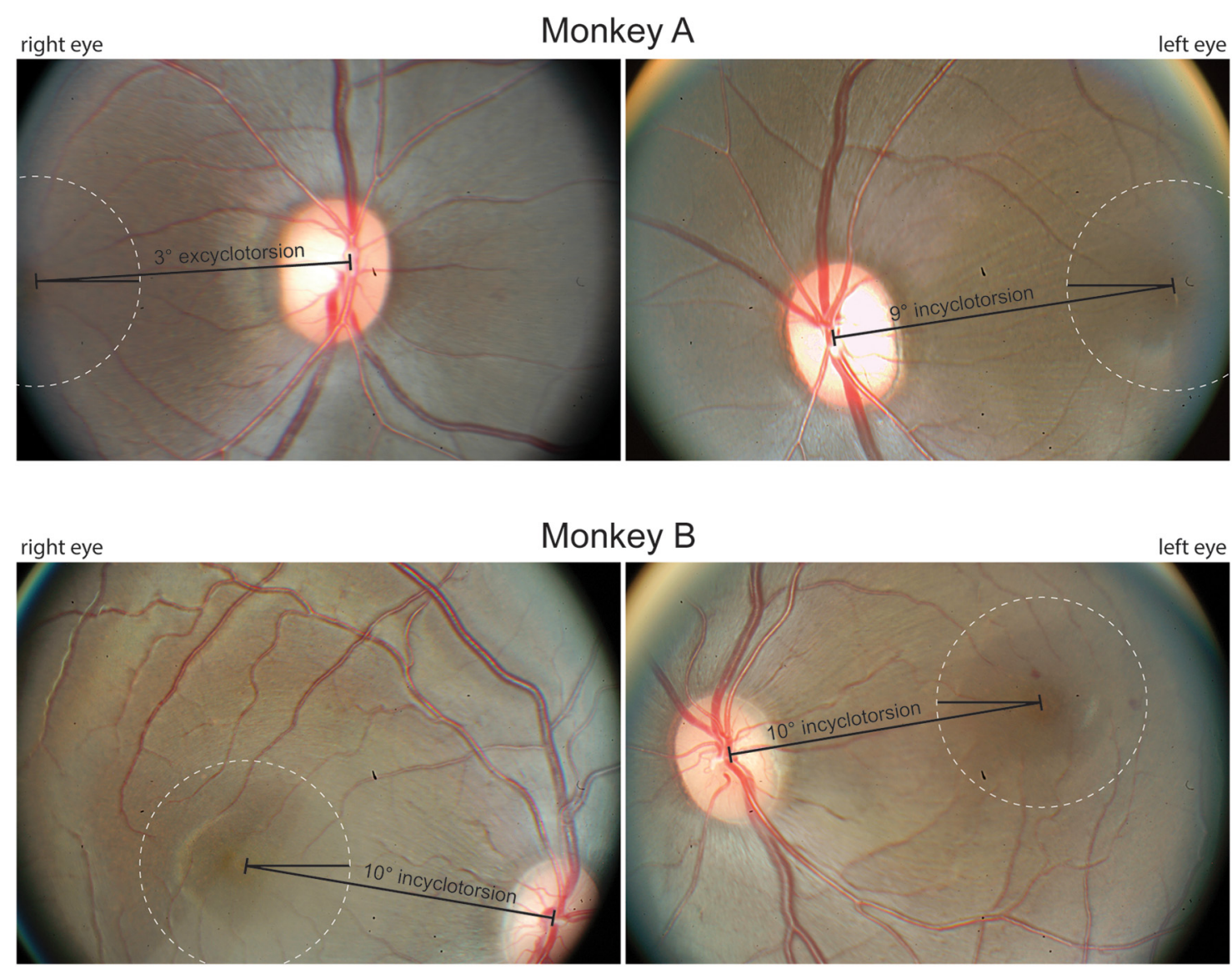

Figure 3. Cyclorotation of eyes in strabismus. Representative pictures show a $6^{\circ}$ relative incyclotorsion of the left eye $\left(9^{\circ}\right.$ counterclockwise) compared with the right eye $\left(3^{\circ}\right.$ counterclockwise) in Monkey A. Monkey B shows a $20^{\circ}$ relative incyclotorsion of the left eye $\left(10^{\circ}\right.$ counterclockwise) compared with the right eye $\left(10^{\circ}\right.$ clockwise).

then averaged to produce an image of the mean stimulus that drove each eye's receptive field under conditions of right eye and left eye fixation.

Ocular dominance. Two ocular dominance indices were computed. The first compared the strength of contralateral versus ipsilateral eye input regardless of the fixating eye. Each neuron's response $(R)$ was defined as the peak of a 2D Gaussian fit to the spike-triggered average stimulus minus the baseline (noise). The ocular dominance index was calculated as follows:

$$
\frac{R_{\text {ipsi }}}{R_{\text {ipsi }}+R_{\text {contra }}}
$$

The second index compared each receptive field's response as a function of fixating versus deviating eye as follows:

$$
\frac{R_{\text {fixating } R F}}{R_{\text {fixatingRF }}+R_{\text {deviating } R F}}
$$


Histograms of both indices were compiled by creating seven equally spaced bins (Hubel and Wiesel, 1962).

\section{Results}

\section{Alignment of sensory and motor maps}

Receptive fields were mapped for 107 cells in Monkey A and 71 cells in Monkey B using a sparse noise stimulus. Figure 1 shows an example from each animal. The animals' task was to fixate a small target located on either the right side or left side of the tangent screen. Because both monkeys had a large exotropia, they fixated with their left eye when the target was on the left and with their right eye when the target was on the right. The fixation target locations were chosen so that only small eye movements were required to alternate fixation when target presentation switched from one side to the other. For some recordings, the fixation targets were adjusted to bring peripheral receptive fields onto the tangent screen.

Once the superior colliculus was identified using a full-field flashing $1 \mathrm{~Hz}$ stimulus, the tetrode was advanced slowly until a cell was isolated. The receptive field in each eye was mapped manually with a computer-generated light spot. After we ascertained that the cell was visually responsive and both eye's receptive fields were located on the tangent screen, the sparse noise stimulus was presented. In some cases, after sparse noise mapping, electrical stimulation was applied to drive staircases of multiple saccades in each eye. The sparse noise stimulus data were analyzed offline to determine the location of the receptive field in each eye. The center of the receptive field was located close to the landing point of the first saccade in each staircase (Fig. 1).

For 29 cells in Monkey A and 31 cells in Monkey B, the receptive fields were mapped simultaneously in each eye using sparse noise and then electrical stimulation was applied.

This allowed us to compare the direction of saccades with the polar angle of receptive field locations (Fig. 2A). There was a strong correlation ( $r=0.99$, Pearson), but some error occurred from unit to unit. This error, equal to saccade direction minus receptive field direction (Fig. $2 B$ ), had a mean absolute value of $6.2 \pm 5.4^{\circ}$. Values were evenly distributed around $0^{\circ}$ (mean value $=0.5 \pm 11.0^{\circ}$ ) and showed no trend related to receptive field eccentricity.

There was also a correlation $(r=0.90)$ between saccade amplitude and the eccentricity of receptive fields (Fig. 2C). Their ratio varied from unit to unit by a mean of $19 \%$. However, the mean of the ratios was $1.02 \pm 0.24(n=60)$, indicating that there was no systematic tendency for saccades to overshoot or undershoot receptive fields. These results show that, in each animal, the topography of the sensory map defined by the polar angle and eccentricity of receptive fields remained well aligned with the motor map for saccade generation. This was true despite the presence of an extremely large exotropia.

\section{Alignment of right eye and left eye maps}

A major issue in strabismus is whether the maps in the superior colliculus serving the right eye and the left eye remain normally aligned in their topography. In Monkey A, microstimulation drove nearly parallel saccades, with a mean direction difference (polar angle OS - polar angle OD) of only $-2.2 \pm 7.4^{\circ}[n=29$; $95 \%$ confidence interval $(\mathrm{CI})=-5.1$ to $0.6^{\circ}$ ]. This difference in motor output was mirrored by the relative position of the receptive fields mapped in each eye (Fig. 1). In Monkey A, the eyes' receptive fields, although displaced on the tangent screen by the animal's ocular deviation, were situated at nearly identical locations with respect to the foveae. There was only a minor rotation with the left eye's fields $\left(-5.2 \pm 13.0^{\circ}, n=107\right.$ cells, $95 \% \mathrm{CI}=$
A right fundus left fundus
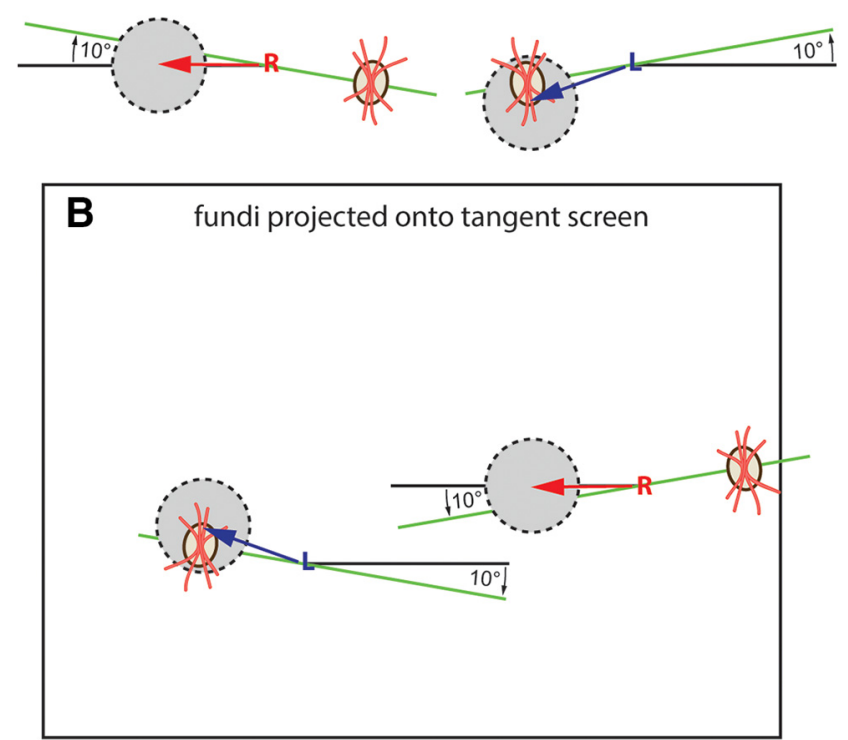

Figure 4. Cyclorotation of eyes corresponds to cyclorotation of receptive fields and saccade vectors. $A$, Schematic diagram showing retinal horizontal raphe (green lines), incyclotorted by $10^{\circ}$ in each fundus of Monkey B (see Fig. 3) relative to the horizon (black lines). The receptive field of a tectal cell is represented by gray shading. It is $15^{\circ}$ in diameter and centered just below the optic disc in the left eye. $\boldsymbol{B}, 0$ n the tangent screen (monkey's view), the projected fundus features are reflected around the horizon (black line). $A 10^{\circ}$ incyclorotation of each globe is additive, so that a pure leftward saccade of the right eye $\left(180^{\circ}\right)$ is accompanied by a saccade in the left eye $\left(160^{\circ}\right)$ that differs $20^{\circ}$ in polar angle, as shown in Figure 1 , bottom left. R, Right fovea; L, left fovea.

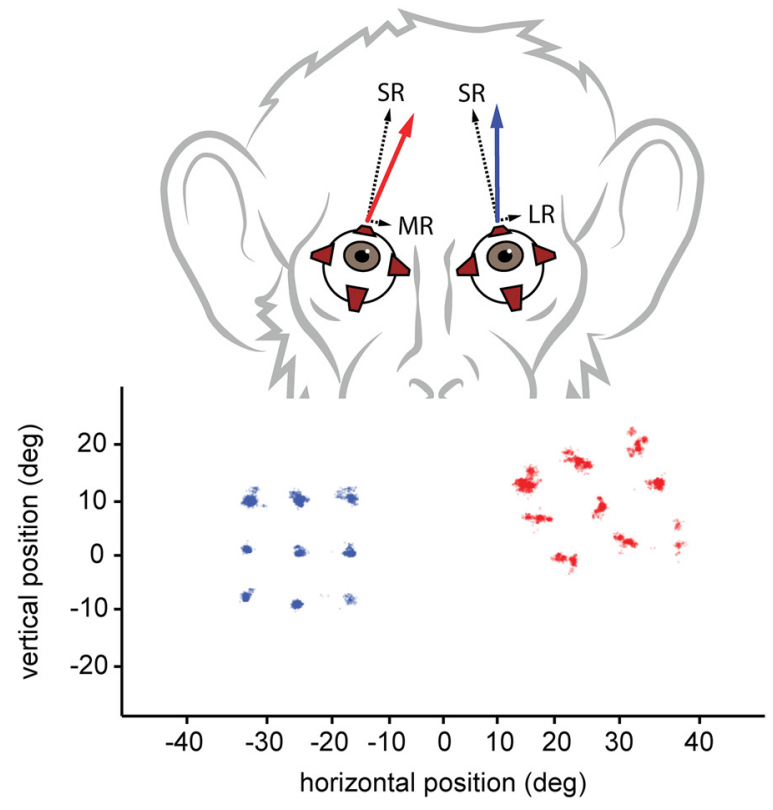

Figure 5. A-pattern exotropia in Monkey B. Eye positions during static fixations by the left eye (blue points) on a grid of 9 targets. The grid of corresponding right eye positions (red points) is rotated by $\sim 20^{\circ}$. Therefore, the exotropia decreases when the animal looks up. In addition, there is a hypertropia of the right eye, which increases with adduction of the left eye. An A-pattern occurs because contraction of the superior rectus muscles in upgaze is accompanied by increased adductive force when the globe is incyclorotated. To look straight up with the left eye (blue arrow), force vectors (dotted lines) must be generated by both the superior rectus (SR) and lateral rectus (LR). Contraction of the $L$ R in the left eye is linked by Herring's law to activation of medial rectus (MR) in the right eye. Combined with contraction of the right superior rectus, this gives rise to a nasalward movement (red arrow) of the right eye in upgaze. 
-7.7 to $\left.-2.7^{\circ}\right)$ relative to those of the right eye. The value was $-4.0 \pm 8.0^{\circ}$ for the 29/107 cells in which electrical stimulation was combined with receptive field mapping. There was no significant difference between the apparent angular rotation of the receptive fields and the saccade direction difference between the two eyes ( $p=$ 0.41, Wilcoxon rank-sum).

In Monkey $\mathrm{B}$, the saccade direction difference was $-21.7 \pm 7.3^{\circ}(n=31)$, meaning that the left eye's saccades were substantially more clockwise than the right eye's saccades. The left eye's receptive fields were rotated $-23.0 \pm 12.8^{\circ}(n=71$ cells; $95 \% \mathrm{CI}=-26.0$ to $\left.-20.0^{\circ}\right)$ relative to the right eye's receptive fields. The value was $-22.2 \pm 10.2^{\circ}$ for the $31 / 77$ cells that combined sensory mapping and microstimulation. As in Monkey A, there was no significant difference between the apparent rotation of the receptive fields and the eyes' saccade direction difference ( $p=0.54$, Wilcoxon rank-sum test).

\section{Impact of eye cyclorotation}

These microstimulation experiments revealed a striking difference in the relative direction of the saccades driven in the left eye versus the right eye in Monkey $\mathrm{A}\left(\right.$ mean $\left.=-2.2^{\circ}\right)$ compared with Monkey B $\left(\right.$ mean $\left.=-21.7^{\circ}\right)$. To investigate the cause, photographs were taken of the ocular fundi while the animals were awake. In Monkey A, the right eye was excyclorotated by $3^{\circ}$ and the left eye was incyclorotated by $9^{\circ}$ (Fig. $3 A$ ). These values sum to a $6^{\circ}$ clockwise rotation of the right eye's retina with respect to that of the left eye. This net rotation equals the mean $-5.2^{\circ}$ (clockwise) shift in the polar angle of the left eye's receptive fields relative to those of the right eye.

In Monkey $\mathrm{B}$, each eye was incyclorotated by $10^{\circ}$ (Fig. $3 \mathrm{~B}$ ). The impact of this cyclorotation is shown schematically in Figure 4. It produced a net $20^{\circ}$ shift clockwise of the right retina relative to the left retina. A clockwise rotation of the fundi results in opposite rotation of receptive field positions on the tangent screen. In this animal, there was a mean $-23^{\circ}$ (clockwise) shift in polar angle of left eye fields relative to right eye fields. The correspondence between rotation of fundi and receptive fields is close. The discrepancy of $3^{\circ}$ could be due to variability in cyclorotation that occurs with different positions of the eyes in their orbits.

Monkey A showed little change in horizontal deviation with changes in vertical gaze angle (see Fig. $5 \mathrm{~A}$, Economides et al., 2016). In contrast, Monkey B showed an "A-pattern," defined as an increase in exotropia with downgaze (Fig. 5). When the left eye fixated statically on a grid of points, the right eye became more exotropic with downgaze and more hypertropic with right gaze. Findings were similar when the right eye fixated on a grid of points, as reported previously (see Fig. 6A, Economides et al., 2016). Incyclotorsion of the globes is likely to account for the A-pattern exotropia in Monkey B (Guyton, 2008).

\section{Preserved binocular responses}

Virtually all 178 neurons recorded in the superior colliculus of these two monkeys responded to stimulation via both eyes (Fig. $6 A)$. The profile of ocular dominance was similar to that reported in normal animals (Schiller, 1984).
In some units, the response was greater in the fixating eye than the deviating eye (Fig. $6 B$ ); in other units, the opposite was true. Overall, fixation behavior did not bias ocular dominance. For the majority of cells, it made little difference which eye was engaged in the act of fixation during visual stimulation.

\section{Absence of anomalous retinal correspondence}

Anomalous retinal correspondence refers to a putative shift in the location of receptive fields in one eye to cancel the ocular deviation. It is an adaptation to misalignment of the eyes that could, in principle, allow preservation of binocular function by aligning retinal loci that were noncorresponding when the eyes were fused, but have become corresponding by virtue of strabismus. In Figure 1, two receptive fields were identified by sparse noise stimulation. It was assumed that a single field belonged to each eye, but it is conceivable that both belonged to the same eye, one with normal retinal correspondence and the other with anomalous correspondence. This cannot be tested simply by occluding either eye because anomalous correspondence disappears during monocular viewing.

To address this issue, recordings were made from the superior colliculus under dichoptic conditions (Fig. 7). A red filter was placed over the right eye and a blue filter over the left eye. These dichroic filters allowed $<0.30 \%$ "cross-talk" by transmission of the blocked color (Economides et al., 2012). Sparse noise containing red, blue, and purple elements was delivered. Red and blue elements were isoluminant after passage through their respective filters. This approach is feasible in the superior colliculus because its neurons are not color tuned (White et al., 2009).

A total of 26 cells in Monkey A and 11 cells in Monkey B were recorded using dichoptic stimulation. All neurons responded binocularly, with red elements revealing a single receptive field in the right eye and blue elements showing a single receptive field in the left eye. The red or blue sparse noise elements never evoked a response at two different locations on the tangent screen or at the same place on the tangent screen.

To address this issue quantitatively, the response was measured to stimulation of either eye at the site of the other eye's receptive field. For example, with the right eye fixating, the magnitude of the spike-triggered average at the site of the right eye's receptive field during left eye stimulation (blue noise elements) was compared with background. A ratio of 1.00 would indicate no response. For our sample of 37 cells, the ratio was $0.95 \pm 0.14$. A pairwise comparison of the values showed no significant dif- 

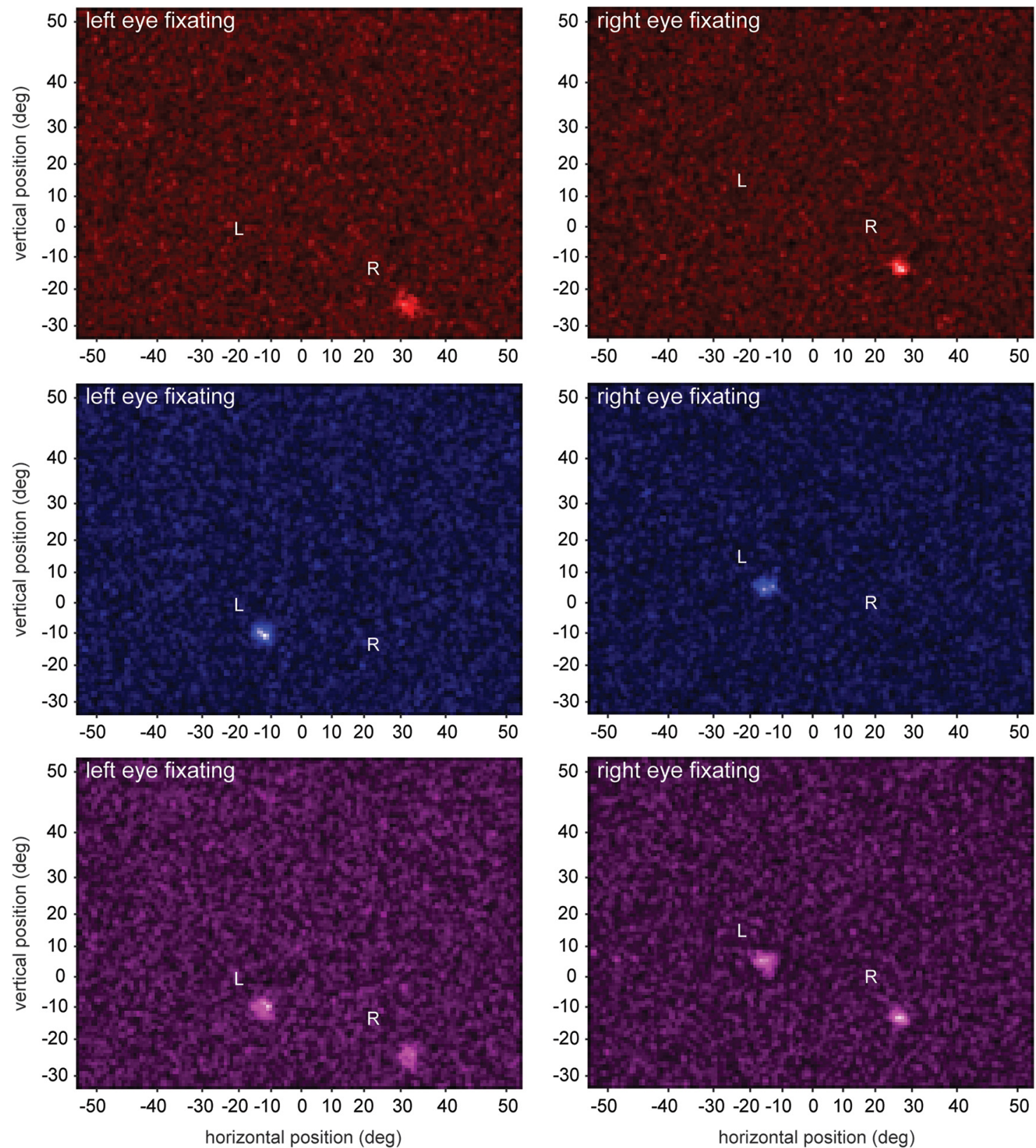

Figure 7. Absence of anomalous retinal correspondence. Dichoptic stimulation in Monkey A was delivered by sparse noise containing red, blue, and purple elements while a red filter was over the right eye and a blue filter over the left eye. Spike-triggered average stimuli (top = red elements, middle = blue elements, bottom = purple elements) show a single receptive field in each eye, with no evidence of anomalous retinal correspondence.

ference between the spike-triggered average stimulus at the anomalous site and the background ( $p=0.65$, Wilcoxon signedrank test). Therefore, under these test conditions, no evidence was found to support the existence of anomalous retinal correspondence in the superior colliculus. This was true for both the fixating eye and the deviating eye.

The lack of anomalous retinal correspondence raises the question of how primates with strabismus make crossover saccades. For the recording in Figure 8, the monkey's task was to saccade to a remembered target after a fixation point disappeared. Each trial began with presentation of a fixation point. After it was acquired, a target was displayed for $100 \mathrm{~ms}$. A variable delay ensued, averaging $400 \mathrm{~ms}$, and then the fixation point was extinguished. This signaled to the monkey that it was free to saccade to the remembered target location.
The monkey viewed the display through colored filters. The blue target generated a sensory response when presented in the left eye's receptive field ( $10^{\circ}$ temporal, $10^{\circ}$ up), followed by a buildup to a motor discharge. When the target landed in the right eye's receptive field, it was visible only to the left eye. The monkey was unable to reach it by making a $30^{\circ}$ adducting saccade with the left eye because of weakness of the medial rectus. Instead, he acquired the target with the right eye. The sensory response was absent, but the buildup and motor phases were similar.

\section{Discussion}

Strabismus might corrupt the topography of the superior colliculus in two ways: by disturbing the alignment between the sensory and motor maps or by shifting the relationship between the maps serving each eye. The main conclusion from this study is that 

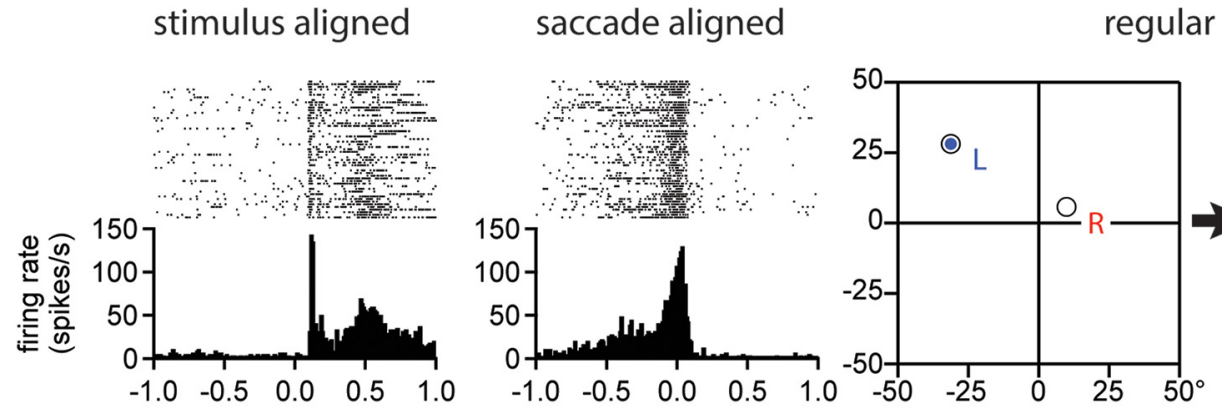

regular saccade

cross-over saccade
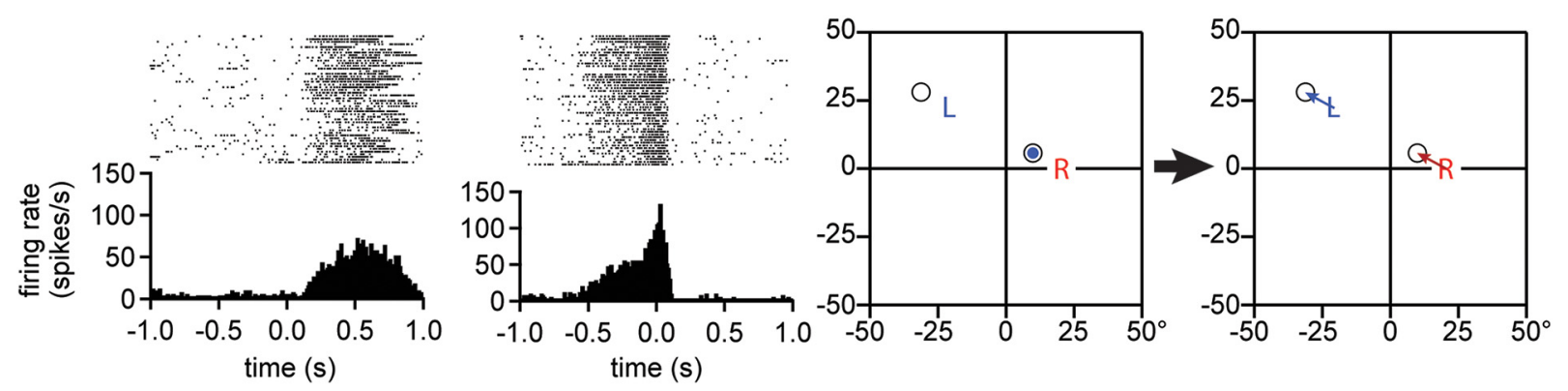

Figure 8. Crossover saccades. Top, The right eye is fixating a point; stimulation is delivered dichoptically with a red filter over the right eye and a blue filter over the left eye. A blue target generates a sensory response when it lands in the left eye's receptive field (stimulus aligned). There is a buildup to a motor response as the monkey waits for the fixation point to extinguish (saccade aligned). Bottom, When the blue target lands in the right eye's receptive field, it is visible to the left eye but reachable only with the right eye, requiring a crossover saccade. The visual response is absent, but the buildup and motor response are similar. L, Left eye's position; R, right eye's position. For economy, other target locations and left eye fixation trials are not shown.

neither phenomenon occurs: the registration of maps in the superior colliculus remains unaltered by strabismus.

Schiller and Stryker (1972) recorded and stimulated in the superior colliculus of normal monkeys and found that the sensory and motor maps are aligned closely. In strabismic monkeys, our experiments also showed a strong correlation between the position of receptive fields and saccade landing points (Figs. 1, 2). To compare results, we extracted the data from that previous study (see Fig. 5 in Schiller and Stryker, 1972). In normal monkeys, saccade direction minus receptive field direction equaled $1.4 \pm$ $4.0^{\circ}$ and saccade amplitude divided by receptive field eccentricity equaled $1.01 \pm 0.16(n=14)$. We obtained $0.5 \pm 11.0^{\circ}$ and $1.02 \pm 0.24$, respectively, for these same parameters in strabismic animals. The mean values in normal and exotropic monkeys are extremely similar, indicating that strabismus does not produce a compensatory global shift in the alignment of sensory maps relative to motor maps. However, in strabismic monkeys, the SDs were greater for both indices. This increased variability suggests that, for any given tectal site, saccades generated by stimulation are more scattered with respect to corresponding receptive field locations. This finding is consistent with the observation that saccades to targets are less accurate in subjects with strabismus (Bucci et al., 2009; Niechwiej-Szwedo et al., 2017). The fault could lie with broader or skewed tuning of tectal cells' motor output or with pathological changes affecting downstream ocular motor pathways.

There was a mean clockwise rotation of $5^{\circ}$ in Monkey A and $23^{\circ}$ in Monkey B of the left eye's receptive fields relative to those of the right eye. This rotation in receptive field locations was accompanied by a commensurate difference in the mean polar angle of saccades produced by microstimulation. Fundus examination revealed a net globe rotation of $6^{\circ}$ in Monkey A and $20^{\circ}$ in Monkey B (Fig. 3). As explained in Figure 4, this relative cyclotorsion of the globes was in the correct direction to explain the shift between the eyes in the polar angle of receptive field locations and saccades. In Monkey A, the shift was small and the fundus cyclorotation was small. In Monkey B, the shift was much larger, as was the relative fundus cyclorotation.

Once fusion is lost, the eyes can become misaligned horizontally, vertically, and torsionally. Horizontal and vertical components are easy to measure, but the latter is usually neglected. Shin and colleagues (2013) have shown that ocular torsion can be detected in $>30 \%$ of exotropic patients when fundus images are examined. Subjects with a larger horizontal deviation tend to have more globe cyclorotation. Surgical correction of exotropia reduces the magnitude of ocular torsion and pattern deviation (Lee et al., 2016, 2017).

The phenomenon of globe rotation in strabismus has been proposed as the cause of A and V pattern deviations (Weiss, 1966; Guyton, 2008). Incyclorotation of the globes displaces the superior recti medially and the inferior recti laterally. The pattern of rotational displacement of the rectus muscles depicted schematically in Figure 5 has been documented with high-resolution orbital imaging in humans with A-pattern exotropia (Hao et al., 2016). It increases the secondary adductive action of the superior rectus in upgaze and decreases the secondary adductive action of the inferior rectus in downgaze, thereby causing an A-pattern. For the monkey to look straight up with the left eye, it must also activate the lateral rectus and, by Hering's law, this will activate the medial rectus in the right eye, contributing to the A-pattern (Fig. 5). Superior oblique muscle overaction is also a factor in A-pattern exotropia (Kushner, 2010).

We performed exactly the same surgery in Monkey A and Monkey B to induce exotropia. It is unclear why tenotomy of the medial recti produced a large incyclotorsion in one animal and not the other. However, the important point is that the large cyclorotation $\left(20^{\circ}\right)$ in Monkey B explains the following: (1) the A-pattern deviation, (2) the clockwise rotation of the left eye's receptive fields 
with respect to those of the right eye, and (3) the clockwise direction difference of left eye versus right eye saccades. All of these phenomena are linked; there is no need to invoke a shift in sensory or motor maps in the superior colliculus to explain them.

In a previous study involving the same two monkeys, we applied microstimulation at multiple sites to test the effect of strabismus on the superior colliculus (Economides et al., 2016). Even if one grants the possibility that displaced monocular motor maps might exist, it would be impossible to activate them separately with electrical current. Simultaneous stimulation of the hypothetically shifted maps would result in a motor output combining signals as a vector sum (Noto and Gnadt, 2009; Katnani et al., 2012; Vokoun et al., 2014). That output would always drive a conjugate movement of the two eyes, assuming that downstream neuronal pathways and orbital structures were normal. Therefore, electrical stimulation is not an ideal way to examine superior colliculus topography in strabismus; one must also plot sensory receptive fields.

Several other groups have also reported the effects of microstimulation on the superior colliculus in strabismic monkeys (Fleuriet et al., 2016; Upadhyaya et al., 2017). Our results are in close agreement. Microstimulation drives similar, but not perfectly conjugate, saccades in the two eyes. The amount of disconjugacy in saccade amplitude and direction varies from animal to animal. This is not surprising, given that each monkey with experimental strabismus shows individual variation in the magnitude of horizontal and vertical misalignment, incomitancy, pattern deviation, globe cyclorotation, extraocular muscle anatomy, and change in deviation with fixation switch. Motor signals are processed at many stages after they leave the superior colliculus; each may contribute to the disconjugacy of saccades in strabismus (Das et al., 2004, 2005; Das and Mustari, 2007). The same pattern of disconjugacy is exhibited during smooth pursuit (Economides et al., 2016) or static fixations (Fig. 5). This is a general property of the eyes, rather than being specific to saccades, and therefore does not originate from saccade-generating cells in the superior colliculus. These points are further addressed in an eloquent review by Walton and colleagues (2017).

The most surprising finding to emerge from this study is that cells retain normal binocular responsivity despite strabismus (Fig. $6 A)$. Overall, the fact that a given eye is engaged in fixation does not bolster its ability to drive cells (Fig. 6B). The only previous studies of the superior colliculus in strabismic animals were done in anesthetized cats. Daily alternating monocular occlusion was reported to cause a strong bias in favor of the contralateral eye, although most cells remained binocularly driven (Gordon and Presson, 1977). Sectioning the medial rectus and lateral rectus in one eye caused an ocular dominance shift toward the normal eye, but only in the colliculus ipsilateral to the operated eye (Gordon and Gummow, 1975). We found no such effects, but our rearing conditions were quite different. Our data are consistent with this previous study in showing that the great majority of tectal cells remains easily driven via either eye in strabismus. This result stands in stark contrast to the dramatic impact of strabismus on striate cortex (Hubel and Wiesel, 1965; Crawford et al., 1996; Mori et al., 2002). One would expect a similar breakdown of binocularity in the superior colliculus, given that its direct retinal input is segregated by eye (Hubel et al., 1975) and its descending cortical input is less binocular. Somehow, the superior colliculus is able to retain binocular function, presumably by integrating direct and indirect monocular inputs. Either different rules govern the response of striate cortex and superior colliculus to loss of fusion or they differ in the timing of their critical periods.
Although binocular function is preserved in the superior colliculus, there is no evidence to suggest the existence of anomalous retinal correspondence (Fig. 7). This means that individual tectal neurons do not encode the size and direction of the animal's ocular deviation. Given that strabismic subjects demonstrate anomalous retinal correspondence and have the ability to saccade accurately to targets acquired via either eye, this determination must be made by neurons at some other site in the brain (Economides et al., 2014, 2012). Cells in the primary somatosensory cortex receive proprioceptive information from the orbit about globe position (Wang et al., 2007). Cats raised with strabismus show a shift in the spatial coordinates of receptive fields in lateral suprasylvian cortex, consistent with anomalous retinal correspondence (Grant and Berman, 1991; Sireteanu and Best, 1992). Perhaps this anomalous shift in topography is mediated by information about eye deviation conveyed from somatosensory cortex. It would be worthwhile to search for anomalous retinal correspondence in extrastriate cortex of awake strabismic monkeys.

How do strabismic subjects make crossover saccades if anomalous retinal correspondence is absent in the superior colliculus (Fig. 8)? The ability to saccade to targets is abolished by cortical blindness. Therefore, it is believed that target information is supplied by descending cortical input. Retinotopic maps remain normal in early cortical areas in strabismic humans with anomalous retinal correspondence (McCormack, 1990). The descending projection from these areas is organized retinotopically (Fries, 1984; Lui et al., 1995), so it cannot inform the superior colliculus about ocular deviation. However, descending input from parietal and frontal cortex is topographically diffuse (Fries, 1985) and may encode the anomalous position of the eyes to allow accurate saccades to a target by either eye. If so, what is the function of the visual response generated by direct retinal input given that accurate saccades can be made without it (Fig. 8)? The retinotectal projection is sizeable, accounting for $10 \%$ of ganglion cells, but it may be vestigial (Perry and Cowey, 1984). It would be intriguing to ablate it selectively to learn how the ability to make saccades is affected.

\section{References}

Adams DL, Economides JR, Jocson CM, Horton JC (2007) A biocompatible titanium headpost for stabilizing behaving monkeys. J Neurophysiol 98: 993-1001. CrossRef Medline

Adams DL, Economides JR, Jocson CM, Parker JM, Horton JC (2011) A watertight acrylic-free titanium recording chamber for electrophysiology in behaving monkeys. J Neurophysiol 106:1581-1590. CrossRef Medline

Adams DL, Economides JR, Horton JC (2017) Incomitance and eye dominance in intermittent exotropia. Invest Ophthalmol Vis Sci 58:4049-4055. CrossRef Medline

Agaoglu MN, LeSage SK, Joshi AC, Das VE (2014) Spatial patterns of fixation-switch behavior in strabismic monkeys. Invest Ophthalmol Vis Sci 55:1259-1268. CrossRef Medline

Basso MA, May PJ (2017) Circuits for action and cognition: a view from the superior colliculus. Annu Rev Vis Sci 3:197-226. CrossRef Medline

Breznen B, Lu SM, Gnadt JW (1996) Analysis of the step response of the saccadic feedback: system behavior. Exp Brain Res 111:337-344. Medline

Bucci MP, Brémond-Gignac D, Kapoula Z (2009) Speed and accuracy of saccades, vergence and combined eye movements in subjects with strabismus before and after eye surgery. Vision Res 49:460-469. CrossRef Medline

Buck D, Powell C, Cumberland P, Davis H, Dawson E, Rahi J, Sloper J, Taylor R, Tiffin P, Clarke MP; Improving Outcomes in Intermittent Exotropia Study Group (2009) Presenting features and early management of childhood intermittent exotropia in the UK: inception cohort study. Br J Ophthalmol 93:1620-1624. CrossRef Medline

Churan J, Guitton D, Pack CC (2012) Spatiotemporal structure of visual receptive fields in macaque superior colliculus. J Neurophysiol 108:26532667. CrossRef Medline

Cooper J, Feldman J (1979) Panoramic viewing, visual acuity of the deviat- 
ing eye, and anomalous retinal correspondence in the intermittent exotrope of the divergence excess type. Am J Optom Physiol Opt 56:422-429. CrossRef Medline

Crawford ML, Harwerth RS, Chino YM, Smith EL 3rd (1996) Binocularity in prism-reared monkeys. Eye 10:161-166. CrossRef Medline

Das VE, Mustari MJ (2007) Correlation of cross-axis eye movements and motoneuron activity in non-human primates with "A" pattern strabismus. Invest Ophthalmol Vis Sci 48:665-674. CrossRef Medline

Das VE, Ono S, Tusa RJ, Mustari MJ (2004) Conjugate adaptation of saccadic gain in non-human primates with strabismus. J Neurophysiol 91:10781084. Medline

Das VE, Fu LN, Mustari MJ, Tusa RJ (2005) Incomitance in monkeys with strabismus. Strabismus 13:33-41. CrossRef Medline

Economides JR, Adams DL, Jocson CM, Horton JC (2007) Ocular motor behavior in macaques with surgical exotropia. J Neurophysiol 98:34113422. CrossRef Medline

Economides JR, Adams DL, Horton JC (2012) Perception via the deviated eye in strabismus. J Neurosci 32:10286-10295. CrossRef Medline

Economides JR, Adams DL, Horton JC (2014) Eye choice for acquisition of targets in alternating strabismus. J Neurosci 34:14578-14588. CrossRef Medline

Economides JR, Adams DL, Horton JC (2016) Normal correspondence of tectal maps for saccadic eye movements in strabismus. J Neurophysiol 116:2541-2549. CrossRef Medline

Fleuriet J, Walton MM, Ono S, Mustari MJ (2016) Electrical microstimulation of the superior colliculus in strabismic monkeys. Invest Ophthalmol Vis Sci 57:3168-3180. CrossRef Medline

Fries W (1984) Cortical projections to the superior colliculus in the macaque monkey: a retrograde study using horseradish peroxidase. J Comp Neurol 230:55-76. CrossRef Medline

Fries W (1985) Inputs from motor and premotor cortex to the superior colliculus of the macaque monkey. Behav Brain Res 18:95-105. CrossRef Medline

Gordon B, Gummow L (1975) Effects of extraocular muscle section on receptive fields in cat superior colliculus. Vision Res 15:1011-1019. CrossRef Medline

Gordon B, Presson J (1977) Effects of alternating occlusion on receptive fields in cat superior colliculus. J Neurophysiol 40:1406-1414. Medline

Grant S, Berman NE (1991) Mechanism of anomalous retinal correspondence: maintenance of binocularity with alteration of receptive-field position in the lateral suprasylvian (LS) visual area of strabismic cats. Vis Neurosci 7:259-281. CrossRef Medline

Griffiths H, Whittle J, Buckley D (2011) The effect of distractors on saccades and adaptation of saccades in strabismus. Vision Res 51:2405-2424. CrossRef Medline

Guyton DL (2008) Ocular torsion reveals the mechanisms of cyclovertical strabismus: the Weisenfeld lecture. Invest Ophthalmol Vis Sci 49:847857, 846. Medline

Hao R, Suh SY, Le A, Demer JL (2016) Rectus extraocular muscle size and pulley location in concomitant and pattern exotropia. Ophthalmology 123:2004-2012. CrossRef Medline

Herzau V (1996) How useful is anomalous correspondence? Eye 10:266269. CrossRef Medline

Hoyt CS, Pesic A (2012) The many enigmas of intermittent exotropia. Br J Ophthalmol 96:1280-1282. CrossRef Medline

Hubel DH, Wiesel TN (1962) Receptive fields, binocular interaction and functional architecture in the cat's visual cortex. J Physiol 160:106-154. CrossRef Medline

Hubel DH, Wiesel TN (1965) Binocular interaction in striate cortex of kittens reared with artificial squint. J Neurophysiol 28:1041-1059. Medline

Hubel DH, LeVay S, Wiesel TN (1975) Mode of termination of retinotectal fibers in macaque monkey: an autoradiographic study. Brain Res 96:2540. CrossRef Medline

Jampolsky A (1963) Physiology of intermittent exotropia. Am Orthopt J 13:5-13. Medline

Katnani HA, Van Opstal AJ, Gandhi NJ (2012) A test of spatial temporal decoding mechanisms in the superior colliculus. J Neurophysiol 107: 2442-2452. CrossRef Medline

Kushner BJ (2010) Effect of ocular torsion on A and V patterns and appar- ent oblique muscle overaction. Arch Ophthalmol 128:712-718. CrossRef Medline

Lee JY, Hwang S, Oh SY, Park KA, Oh SY (2016) Postoperative change in ocular torsion in intermittent exotropia: relationship with postoperative surgical outcomes. PLoS One 11:e0162819. CrossRef Medline

Lee YB, Rhiu S, Lee JY, Choi MY, Paik HJ, Lim KH, Choi DG (2017) Effect of horizontal rectus surgery for the correction of intermittent exotropia on sub-A or sub-V pattern. PLoS One 12:e0179626. CrossRef Medline

Lui F, Gregory KM, Blanks RH, Giolli RA (1995) Projections from visual areas of the cerebral cortex to pretectal nuclear complex, terminal accessory optic nuclei, and superior colliculus in macaque monkey. J Comp Neurol 363:439-460. CrossRef Medline

McCormack G (1990) Normal retinotopic mapping in human strabismus with anomalous retinal correspondence. Invest Ophthalmol Vis Sci 31: 559-568. Medline

Mori T, Matsuura K, Zhang B, Smith EL 3rd, Chino YM (2002) Effects of the duration of early strabismus on the binocular responses of neurons in the monkey visual cortex (V1). Invest Ophthalmol Vis Sci 43:1262-1269. Medline

Niechwiej-Szwedo E, Goltz HC, Colpa L, Chandrakumar M, Wong AM (2017) Effects of reduced acuity and stereo acuity on saccades and reaching movements in adults with amblyopia and strabismus. Invest Ophthalmol Vis Sci 58:914-921. CrossRef Medline

Noto CT, Gnadt JW (2009) Saccade trajectories evoked by sequential and colliding stimulation of the monkey superior colliculus. Brain Res 1295: 99-118. CrossRef Medline

Nusz KJ, Mohney BG, Diehl NN (2006) The course of intermittent exotropia in a population-based cohort. Ophthalmology 113:1154-1158. CrossRef Medline

Perry VH, Cowey A (1984) Retinal ganglion cells that project to the superior colliculus and pretectum in the macaque monkey. Neuroscience 12:11251137. CrossRef Medline

Robinson DA (1972) Eye movements evoked by collicular stimulation in the alert monkey. Vision Res 12:1795-1808. CrossRef Medline

Schiller PH, Stryker M (1972) Single-unit recording and stimulation in superior colliculus of the alert rhesus monkey. J Neurophysiol 35:915-924. Medline

Schiller PH (1984) The superior colliculus and visual function. In: The handbook of physiology, Vol 3 (JM Brookhart, VB Mountcastle, eds.), pp 457-505. Philadelphia, Pennsylvania: Lippincott Williams and Wilkins.

Shin KH, Lee HJ, Lim HT (2013) Ocular torsion among patients with intermittent exotropia: relationships with disease severity factors. Am J Ophthalmol 155:177-182. CrossRef Medline

Sireteanu R, Best J (1992) Squint-induced modification of visual receptive fields in the lateral suprasylvian cortex of the cat: binocular Interaction, vertical effect and anomalous correspondence. Eur J Neurosci 4:235-242. CrossRef Medline

Stryker MP, Schiller PH (1975) Eye and head movements evoked by electrical stimulation of monkey superior colliculus. Exp Brain Res 23:103-112. Medline

Upadhyaya S, Meng H, Das VE (2017) Electrical stimulation of superior colliculus affects strabismus angle in monkey models for strabismus. J Neurophysiol 117:1281-1292. CrossRef Medline

Vokoun CR, Huang X, Jackson MB, Basso MA (2014) Response normalization in the superficial layers of the superior colliculus as a possible mechanism for saccadic averaging. J Neurosci 34:7976-7987. CrossRef Medline

Walton MMG, Pallus A, Fleuriet J, Mustari MJ, Tarczy-Hornoch K (2017) Neural mechanisms of oculomotor abnormalities in the infantile strabismus syndrome. J Neurophysiol 118:280-299. CrossRef Medline

Wang X, Zhang M, Cohen IS, Goldberg ME (2007) The proprioceptive representation of eye position in monkey primary somatosensory cortex. Nat Neurosci 10:640-646. CrossRef Medline

Weiss JB (1966) Ectopies et pseudoectopies maculaires par rotation. Bull Mem Soc Fr Ophtal 79:329-349.

White BJ, Boehnke SE, Marino RA, Itti L, Munoz DP (2009) Color-related signals in the primate superior colliculus. J Neurosci 29:12159-12166. CrossRef Medline

Wurtz RH, Albano JE (1980) Visual-motor function of the primate superior colliculus. Annu Rev Neurosci 3:189-226. CrossRef Medline 